\title{
Vitamin D Deficiency and Clinically Detected Scoliosis among Male Adolescents at High-Altitude Area in Southwestern Saudi Arabia
}

\author{
Abdullah Assiri ${ }^{1}$, Ahmed A. Mahfouz ${ }^{2,3 \star}$, Nabil J. Awadalla ${ }^{2,4}$, Ahmed Y. Abolyazid ${ }^{2,4}$, Medhat Shalaby ${ }^{1,5}$ \\ ${ }^{1}$ Department of Internal Medicine, College of Medicine, King Khalid University, Abha 61421, Saudi Arabia; ${ }^{2}$ Department of \\ Family and Community Medicine, College of Medicine, King Khalid University, Abha 61421, Saudi Arabia; ${ }^{3}$ Department of \\ Epidemiology, High Institute of Public Health, Alexandria University, Alexandria 21511, Egypt; ${ }^{4}$ Department of Community \\ Medicine, College of Medicine Mansoura University, Mansoura 35516, Egypt; ${ }^{5}$ Department of Rheumatology, Faculty of \\ Medicine, Al Azhar University, Cairo 11651, Egypt
}

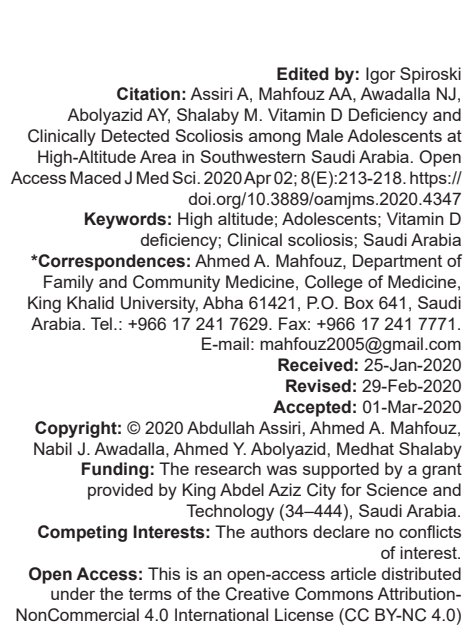

Introduction

Vitamin $D$ is formed in the skin, under the effect of ultraviolet $B$ radiation. Vitamin $D$ deficiency $(V D D)$ is currently documented as prevalent in several areas of the globe including North America, Europe, and the Middle East [1]. A recent study in a Gulf country, Kuwait, reported a high prevalence of VDD among adolescents in spite of the excess sunlight, which may reveal strong sun avoidance behavior [2]. Similarly, a study in Saudi Arabia, in three different regions (central, western, and eastern regions), showed a prevalence of $49.5 \%$ of VDD among school students [3].

The prevalence rates of schoolchildren scoliosis vary widely worldwide. A systematic review of 20 studies performed between 1977 and 2011 found a prevalence rate of scoliosis among schoolchildren ranging from $1 \%$ to $14.8 \%$ [4]. A recent study in Iran published in 2018 found a prevalence of clinical scoliosis of $10.4 \%$ among schoolchildren [5]. A local study in Abha City found a higher prevalence rate of $19.1 \%$ among adolescents [6].

Studies suggest an association between VDD and musculoskeletal problems such as adolescent scoliosis [7]. A study in India documented the significant association between VDD and musculoskeletal problems [8]. In Hong Kong, researchers found also that VDD has a significant role in the development of scoliosis [9].

Taking into consideration that the most common reason for VDD being inadequate sunlight exposure, it is not astonishing that countries at high altitude have high occurrence of VDD [10]. Aseer region (population 2,211,000) is situated in the southwest of Saudi Arabia extended over an area of more than $80,000 \mathrm{~km}^{2}$. The city of Abha is the capital of Aseer and is located at an altitude of $2270 \mathrm{~m}$ (7500 feet) [11].

The aims of the current work were to explore Vitamin D status, to examine the association of VDD and clinically detected scoliosis, and to find a cutoff 
point of Vitamin D level predicting clinical scoliosis among adolescents in Abha City.

\section{Materials and Methods}

\section{Study setting}

The study was conducted among male students from intermediate and secondary schools in Abha City.

\section{Design}

A nested case-control design in a $1: 3$ ratio was performed on a sample of male adolescents in Abha City. Screening for scoliosis was performed. Out of 417 surveyed adolescents, we identified 90 positive adolescents. More details of this cross-sectional study were published before [6]. Of the identified positive cases, 62 persons approved to provide a blood sample. They were matched by age in a 1:3 ratio individually. Of the 327 adolescents free from scoliosis, 205 were selected as controls and gave blood samples.

\section{Clinical screening for scoliosis}

Screening of students was clinically accomplished in an isolated place to keep the privacy and self-respect of the students [6]. The Adam's forward bending test joined with the measurement of angle of trunk inclination (ATI) by scoliometer (Orthopedic Systems Inc., Union City, California, USA) was executed, while permitting the upper limbs to suspend freely with the palms opposed in a comfortable way [12]. Adolescents with an ATI measurement of $\geq 5$ degrees were considered positive for clinical scoliosis screening [13].

The study proposal was approved by the Ethical Committee of King Khalid University. Parental approval on paper was taken. Pupils absent during the survey were not included. All required official approvals were taken.

\section{Vitamin D assessment}

Serum level of 25-hydroxyvitamin D [25(OH)D] was assessed using enzyme-linked immunosorbent assay technique. Levels $<25 \mathrm{nmol} / \mathrm{L}$ were considered as VDD [14].

\section{Data analysis}

Data were explored using SPSS. Frequency, arithmetic mean, mode, median, standard deviation, and skewness were used to present the data. Chi-square,
Mann-Whitney U, and one-sample Kolmogorov-Smirnov were used as tests of significance at $5 \%$ level.

A receiver operating characteristic (ROC) curve was created to predict the role of Vitamin $D$ in identifying adolescents with clinical scoliosis. It showed the performing of the cutoff points in terms of sensitivity versus 1-specificity. The area under the curve (AUC) is an estimate of the accurateness of cutoff point. The AUC estimate lies between 0.5 and 1 . Values $<0.6$ indicate a weak classifier and 1 indicates an outstanding classifier.

To examine Vitamin D association with clinical scoliosis, crude odds ratio and concomitant 95\% confidence intervals were computed. Multivariable binary logistic regression analysis was calculated to assess the adjusted odds ratio and the concomitant $95 \%$ confidence intervals.

\section{Results}

The current research paper included 267 male adolescents. Out of them, 62 were clinically positive for scoliosis and the rest (205) were not. The sample included 73 students from intermediate level (aged 13-16 years) and 194 from secondary level (aged 17+ years).

\section{Vitamin D levels}

The overall Vitamin $D$ level among the study sample of male adolescents ranged from 9 to $74.0 \mathrm{nmol} / \mathrm{L}$ with an average of $25.27 \pm 12.06 \mathrm{nmol} / \mathrm{L}$, a mode of $17.4 \mathrm{nmol} / \mathrm{L}$, and a median of $21.6 \mathrm{nmol} / \mathrm{L}$. Figure 1 and results of one-sample KolmogorovSmirnov test $(\mathrm{KS}=0.218, \mathrm{p}=0.001$ ) showed that the distribution of Vitamin $\mathrm{D}$ was not normally distributed. The distribution has a mean value more than the mode and skewness value of 1.759 (standard error 0.149), indicating positive skewness to the right. Overall results showed that more than two-thirds $(68.5 \%, 183)$ of male adolescents were diagnosed having VDD ( $<25 \mathrm{nmol} / \mathrm{L})$.

\section{scoliosis \\ Vitamin D levels by clinically detected}

Vitamin $D$ level among adolescents free from scoliosis varied from $9 \mathrm{nmol} / \mathrm{L}$ to $74.0 \mathrm{nmol} / \mathrm{L}$ with a median of $22.6 \mathrm{nmol} / \mathrm{L}$ and an average of $27.01 \pm 13.03$ $\mathrm{nmol} / \mathrm{L}$. On the other hand, Vitamin D levels among adolescents with clinical scoliosis were lower, ranging from 10.10 to $31.60 \mathrm{nmol} / \mathrm{L}$ with a median of $18.65 \mathrm{nmol} / \mathrm{L}$ and an average of $19.25 \pm 4.28 \mathrm{nmol} / \mathrm{L}$. The difference was statistically significant (Mann-Whitney $U, Z=4.825$, $p=0.001)$. Figure 2 presents the 95\% confidence intervals of Vitamin D level averages among adolescents 


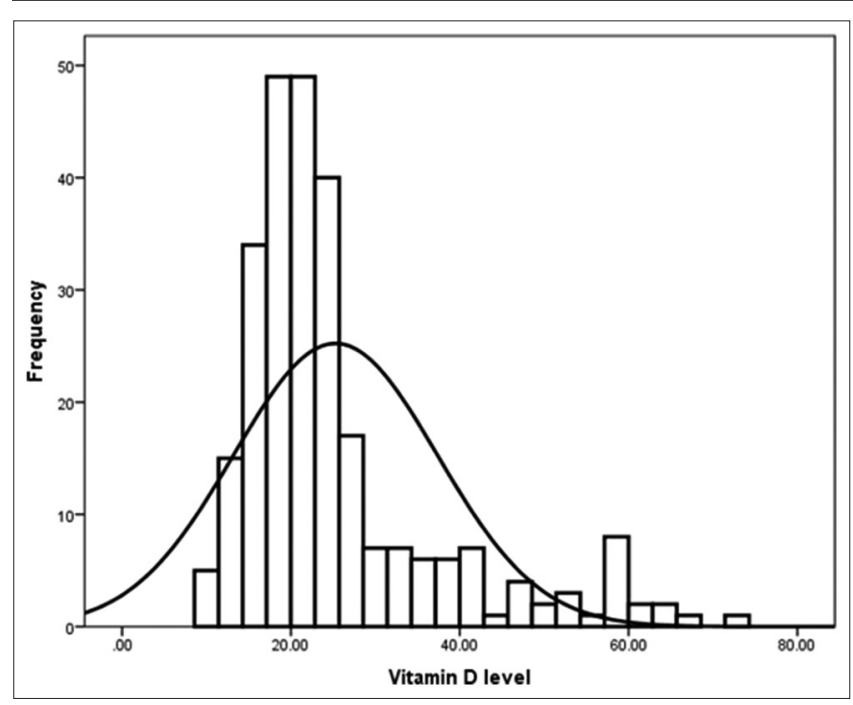

Figure 1: Distribution of Vitamin $D$ values (nmol/L) among the study sample of male adolescents at Abha City

with $($ Mean $=19.25 \mathrm{nmol} / \mathrm{L}, 95 \% \mathrm{Cl}$ : 18.17-20.34 $\mathrm{nmol} / \mathrm{L}$ ) and without clinical scoliosis (Mean $=27.09$ $\mathrm{nmol} / \mathrm{L}, 95 \% \mathrm{Cl}: 25.31-28.89 \mathrm{nmol} / \mathrm{L})$. The lack of overlap denotes significant differences between both groups.

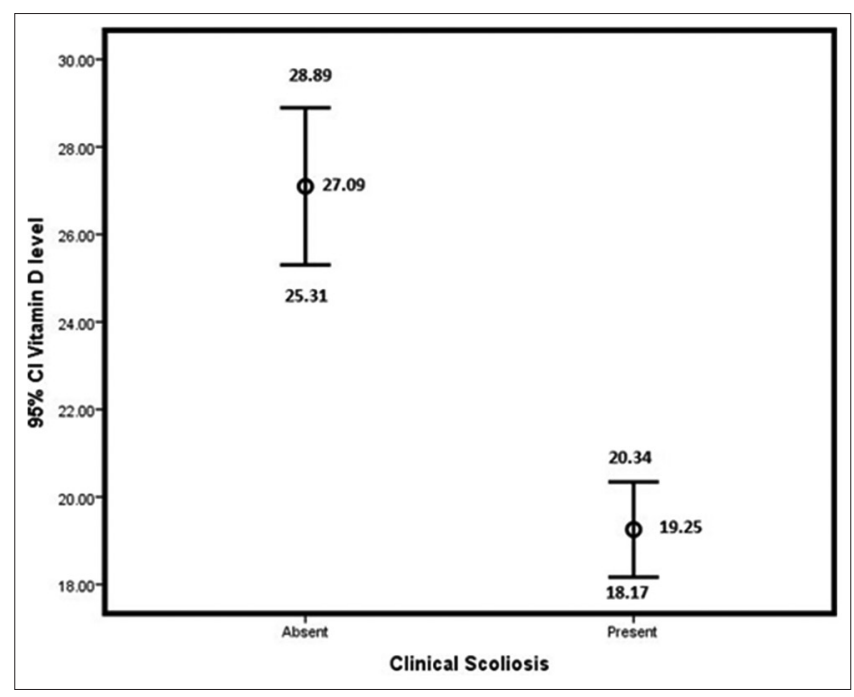

Figure 2: Error bars showing 95\% confidence intervals (95\% Cl) of Vitamin $D$ averages among adolescents with and without clinical scoliosis at Abha City

VDD (<25 nmol/L) among cases with clinical scoliosis amounted to $91.9 \%$ (57) compared to $61.5 \%$ (126) among adolescent free from clinical scoliosis. The risk of clinical scoliosis was significantly higher among adolescents with VDD compared to those without deficiency (cOR $=7.15,95 \% \mathrm{Cl}: 2.74-18.60)$. In a multivariable logistic regression adjusting for grade, the adjusted odds ratio amounted to 6.88 (95\% Cl: 2.63-17.99).

\section{Prediction of clinical scoliosis by Vitamin D level}

Table 1 and Figure 3 show ROC curve analysis of the prediction ability of Vitamin $\mathrm{D}$ level for clinical
Table 1: Result of receiver operating characteristic for Vitamin D level in $\mathrm{nmol} / \mathrm{L}$ to predict clinical scoliosis at Abha City

\begin{tabular}{lllll}
\hline $\begin{array}{l}\text { Clinical } \\
\text { condition }\end{array}$ & AUC $(95 \% \mathrm{Cl})$ & $\begin{array}{l}\text { Optimal cutoff point of } \\
\text { Vitamin D nmol/L }\end{array}$ & $\begin{array}{l}\text { Sensitivity \% } \\
(95 \% \mathrm{Cl})\end{array}$ & $\begin{array}{l}\text { Specificity \% } \\
(95 \% \mathrm{Cl})\end{array}$ \\
\hline Clinical & 0.702 & $\leq 20.2$ & 62.9 & 66.8 \\
scoliosis & $(0.643-0.756)$ & & $(49.7-74.8)$ & $(59.9-73.2)$ \\
\hline
\end{tabular}

AUC: Area under the curve, $95 \% \mathrm{Cl}: 95 \%$ confidence interval.

scoliosis. The ability of Vitamin D, expressed as a continuous variable, to predict clinical scoliosis was good (AUC $=0.702,95 \% \mathrm{Cl}:$ 0.643-0.756). The ROC curve identified the optimal cutoff point of Vitamin $D$ to be $\leq 20.2 \mathrm{nmol} / \mathrm{L}$. The corresponding sensitivity was $62.9 \%(95 \% \mathrm{Cl}: 49.7-74.8)$ and the specificity was $66.8 \%$ (95\% Cl: 59.9-73.2).

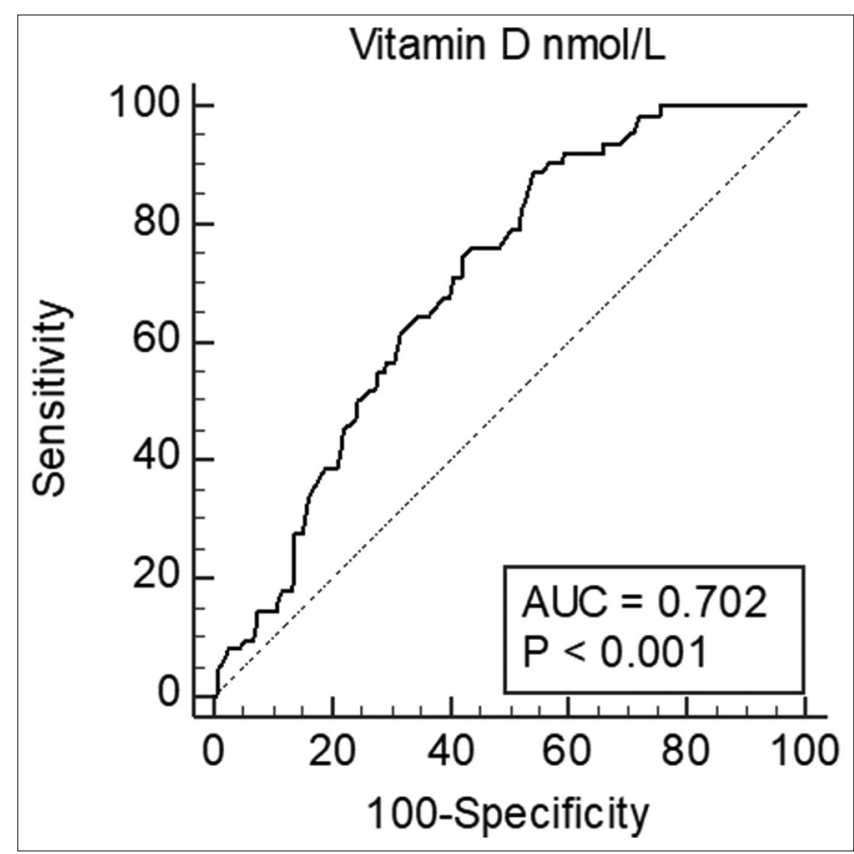

Figure 3: Receiver operating characteristic curve analysis of Vitamin $D$ level in $\mathrm{nmol} / \mathrm{L}$ to predict clinical scoliosis among study sample of school adolescents at Abha City

\section{Discussion}

Vitamin D performs a chief physiological function in keeping extracellular calcium ion levels in the body. Extracellular calcium is essential for the performance of many processes and activities. Vitamin $D$ affects calcium levels by managing the absorption of calcium from the intestine and through its impacts on parathyroid hormone production [15]. Vitamin $\mathrm{D}$ is obtained both through dietary means $(10-20 \%)$ and by the production through the skin under the effect of sunlight (80-90\%) [15]. Values $<25 \mathrm{nmol} / \mathrm{L}$ were considered as VDD [14]. The current work showed that the average value of the serum Vitamin D was $25.27 \mathrm{nmol} / \mathrm{L}$ and more than two-thirds (68.5\%) of the study sample of male adolescents suffered from $\operatorname{VDD}(<25 \mathrm{nmol} / \mathrm{L})$. Studies from the globe indicate that hypovitaminosis $D$ is prevalent and is regarded as a 
general health issue [15], [16], [17]. There are consistent data suggestive of highest prevalence of VDD in Asia, the Middle East, and Africa [18].

A recent study in Jeddah in Saudi Arabia (sea level sunny city) on 303 adolescents aged 13-19 years revealed a prevalence of VDD of $34.4 \%$ and the mean concentration of $25(\mathrm{OH}) \mathrm{D}$ of $32.6 \mathrm{nmol} / \mathrm{L}$ [19]. This Vitamin $\mathrm{D}$ status was much better than that reported in the current study. This difference could partly be explained by the difference in altitude and sun exposure between the two study areas.

Latitude and relevant lifestyle factors could be of significant importance to Vitamin $D$ condition in racial clusters with dark skin (e.g., African, Middle Eastern, and South Asian), who are at present at higher chance of VDD due to melanin density, dress mode, sun protection behavior, and genetics [10]. Altitude is another issue that influences skin synthesis of Vitamin D. At high altitudes, cloudy weather may interfere with ultraviolet $B$ radiation. Published articles on altitude and Vitamin D synthesis are inadequate. However, it is recognized that altitude minimizes the duration of Vitamin D production [20]. A high occurrence of VDD $(81 \%)$ was observed among children living in two districts situated at high altitude of Himachal Pradesh, India [21]. The subjects with VDD amounted to $83.8 \%$ in another high-altitude area in India [22]. A study among Argentinean children showed that $46.5 \%$ living at high altitude suffered from VDD [23]. Abha City lies at an altitude of $2270 \mathrm{~m}$ [11]. Being at high altitude, it is expected to find low Vitamin D, especially during winter period, where there is no sunlight of suitable wavelength for production of cutaneous pre-Vitamin D. Cloudy weather may also reduce Vitamin $D$ level by minimizing sunlight exposure. This condition may augment the situation of VDD among adolescents in Abha City.

Adolescent scoliosis is a disease of public health significance both globally and in Saudi Arabia. It is a multifactorial disease with uncertain primary etiology and pathogenesis [24]. The potential role of Vitamin-D in the developing adolescent scoliosis is recently being considered [25], [26]. The results of the present study provide adequate evidence of a positive relation between VDD ( $<25 \mathrm{nmol} / \mathrm{L})$ and clinically detected scoliosis in adolescents. This finding is similar to results obtained by previously conducted studies which demonstrated that the level Vitamin $\mathrm{D}$ was significantly lower in patients with scoliosis than in healthy age- and sex-matched controls [25], [26], [27]. The mechanisms of Vitamin $D$ in the pathogenesis of scoliosis are still uncertain. A recent review study assumed that VDD increases the risk of scoliosis development by its influence on the regulation of fibrosis, postural control, and bone mineral density [9]. Another explanation for the role of Vitamin $D$ in the development of scoliosis was made by another review study which postulated that Vitamin D levels at high-altitude areas are decreased and delays the onset of puberty which, in turn, increases the vulnerability of vertebral column and increases the prevalence of scoliosis [28]. This could explain the observed higher prevalence of scoliosis among male adolescents in Abha City [6] which located at high altitude [11]. Identifying the role of Vitamin D in the development of scoliosis could suggest the preventive role of Vitamin D supplementation. Furthermore, Vitamin D supplementation could improve bone health and minimize spine curvature in scoliotic patients [29].

In the present study, a trial has been done to identify a clear threshold cutoff of Vitamin D level to predict clinically detected scoliosis. The results of ROC curve analysis showed acceptable discriminative ability of Vitamin $\mathrm{D}$ to predict scoliosis at a threshold value of $\leq 20.2 \mathrm{nmol} / \mathrm{L}$. No similar analysis has been undertaken previously. Hence, comparison with other studies is difficult. However, these results provide further evidence that preventing VDD (keeping Vitamin D level above 20 $\mathrm{nmol} / \mathrm{L}$ ) could help in minimizing the burden of scoliosis, especially at high-altitude areas.

The present study documented for the $1^{\text {st }}$ time the high prevalence of VDD in high-altitude areas in Saudi Arabia. Furthermore, the present study revealed the positive association of VDD and clinical scoliosis. Similar findings were reported in different regions in Turkey [25], Poland [26], and Brazil [27].

\section{Conclusions}

The finding of overall levels of Vitamin $D$ in the study adolescents suggests a high prevalence of VDD in a high-altitude area in Southwest Saudi Arabia. There is adequate evidence for a positive association between VDD and clinically detected scoliosis. It is possibly that Vitamin D plays a role in the etiology and pathogenesis of adolescent scoliosis at high-altitude areas. A threshold cutoff value of $20.2 \mathrm{nmol} / \mathrm{L}$ has been identified to predict clinically detected scoliosis. A larger populationbased study involved both males and females and different levels of altitudes are warranted. Furthermore, prospective studies are recommended to provide a higher level of evidence regarding the relationship of Vitamin D with scoliosis among adolescents. The role of possible preventive and therapeutic effect of Vitamin D supplementation should be thoroughly considered by school health authorities.

\section{Acknowledgments}

We would like to acknowledge the schools and students who participated in this study. We would also 
like to thank the research assistants who participated in data collection.

\section{References}

1. Hamilton B, Grantham J, Racinais S, Chalabi H. Vitamin D deficiency is endemic in Middle Eastern sportsmen. Public Health Nutr. 2010;13(10):1528-34. https://doi.org/10.1017/ s136898000999320x

PMid:20074396

2. Al-Taiar A, Rahman A, Al-Sabah R, Shaban L, Al-Harbi A. Vitamin D status among adolescents in Kuwait: A cross-sectional study. BMJ Open. 2018;8(7):e021401. https://doi.org/10.1136/ bmjopen-2017-021401

PMid:30068613

3. Kaddam IM, Al-Shaikh AM, Abaalkhail BA, Asseri KS, Al-Saleh YM, Al-Qarni AA, et al. Prevalence of Vitamin D deficiency and its associated factors in three regions of Saudi Arabia:A cross-sectional study. Saudi Med J. 2017;38(4):381-90. https://doi.org/10.15537/smj.2017.4.18753 PMid:28397944

4. Suh SW, Modi HN, Yang JH, Hong JY. Idiopathic scoliosis in Korean schoolchildren: A prospective screening study of over 1 million children. Eur Spine J. 2011;20(7):1087-94. https://doi. org/10.1007/s00586-011-1695-8

PMid:21274729

5. Moalej S, Asadabadi M, Hashemi R, Khedmat L, Tavacolizadeh R, Vahabi Z, et al. Screening of scoliosis in school children in Tehran: The prevalence rate of idiopathic scoliosis. J Back Musculoskeletal Rehabil. 2018;31(4):767-74. https://doi.org/10.3233/bmr-171078

PMid:29578478

6. Assiri A, Mahfouz AA, Awadalla NJ, Abolyazid AY, Shalaby M, Abogamal A, et al. School screening for scoliosis among male adolescents in Abha city, Southwestern Saudi Arabia. Health Sci. 2019;8(4):190-5. https://doi.org/10.3390/ijerph17010005

7. Kiebzak GM, Neal KM, Hosseinzadeh P, Olney RC, Levine MA. Pitfalls with Vitamin $D$ research in musculoskeletal disorders and recommendations on how to avoid them. J Clin Res Pediatr Endocrinol. 2019;11(3):220-6. https://doi.org/10.4274/jcrpe. galenos.2019.2019.0007

PMid:30759962

8. Hanuman AM, Satyaprasad J, Rao VN, Swamy CH. Prevalence of Vitamin-D deficiency in patients attending ortho OPD with vague musculoskeletal complaints and their response to oral Vitamin-D supplementation: An interventional study. Int J Orthop. 2019;5(4):976-9. https://doi.org/10.22271/ortho.2019. v5.i4q.1804

9. Ng SY, Bettany-Saltikov J, Cheung IY, Chan KK. The role of Vitamin $\mathrm{D}$ in the pathogenesis of adolescent idiopathic scoliosis. Asian Spine J. 2018;12(6):1127-45. https://doi.org/10.31616/ asj.2018.12.6.1127

PMid:30322242

10. Mendes MM, Darling AL, Hart KH, Morse S, Murphy RJ, Lanham-NewSA. Impact of high latitude, urban living and ethnicity on 25-hydroxy Vitamin D status: A need for multidisciplinary action? J Steroid Biochem Mol Biol. 2019;188:95-102. https:// doi.org/10.1016/j.jsbmb.2018.12.012

PMid:30610914

11. The Saudi Network. Abha City Profile. Available from: http://www. the-saudi.net/saudi-arabia/abha/abha_city.htm. [Last accessed on 2019 Dec 19]. https://doi.org/10.21474/ijar01/2296

12. Côté P, Kreitz BG, Cassidy JD, Dzus AK, Martel J. A study of the diagnostic accuracy and reliability of the Scoliometer and Adam's forward bend test. Spine (Phila Pa 1976). 1998;23(7):796-802. https://doi.org/10.1097/00007632-199804010-00011 PMid:9563110

13. Huang SC. Cut-off point of the Scoliometer in school scoliosis screening. Spine (Phila Pa 1976). 1997;22(17):1985-9. https:// doi.org/10.1097/00007632-199709010-00007 PMid:9306527

14. Rosen CJ, Abrams SA, Aloia JF, Brannon PM, Clinton SK, Durazo-Arvizu RA, et al. IOM committee members respond to endocrine society Vitamin D guideline. J Clin Endocrinol Metab. 2012;97(4):1146-52. https://doi.org/10.1210/jc.2011-2218 PMid:22442278

15. Mithal A, Wahl D, Bonjour J, Burckhardt P, Dawson-Hughes B Global Vitamin D status and determinants of hypovitaminosis D. Osteoporos Int. 2009;20(11):1807-20. https://doi.org/10.1007/ s00198-009-0954-6 PMid: 19543765

16. Palacios C, Gonzalez L. Is Vitamin D deficiency a major global public health problem? J Steroid Biochem Mol Biol. 2014;144:138-45. https://doi.org/10.1016/j.jsbmb.2013.11.003 PMid:24239505

17. Roth DE, Abrams SA, Aloia J, Bergeron G, Bourassa MW, Brown $\mathrm{KH}$, et al. Global prevalence and disease burden of Vitamin $D$ deficiency: A roadmap for action in low-and middleincome countries. Ann N Y Acad Sci. 2018;1430(1):44-79. https://doi.org/10.1111/nyas.13968 PMid:30225965

18. Edwards M, Cole Z, Harvey N, Cooper C. The global epidemiology of Vitamin D status. J Aging Res Clin Prac. 2014;3(3):148-58. PMid:29080639

19. Mansouri H, AIRaddadi R. Bone health markers of a representative group of Saudi adolescents in Jeddah. Clin Exp Obstetrics Gynecol. 2018;45(6):893-6.

20. Engelsen O, Brustad M, Aksnes L, Lund E. Daily duration of Vitamin $D$ synthesis in human skin with relation to latitude, total ozone, altitude, ground cover, aerosols and cloud thickness. Photochem Photobiol. 2005;81(6):1287-90. https://doi. org/10.1562/2004-11-19-rn-375

PMid: 16354110

21. Kapil U, Pandey RM, Sharma B, Ramakrishnan L, Sharma N, Singh G, et al. Prevalence of Vitamin D deficiency in children (6-18 years) residing in Kullu and Kangra districts of Himachal Pradesh, India. Indian J Pediatr. 2018;85(5):344-50. https://doi. org/10.1007/s12098-017-2577-9 PMid:29292488

22. Sharma N, Sharma B, Singh G, Gupta A, Sharma R, Kapil U. Vitamin $D$ status in cold trans-himalayan deserts at altitude of 4000 meter and above in India. Indian J Community Health. 2018;30(4):400-2.

23. Hirschler V, Maccallini G, Molinari C, Aranda C. Low Vitamin D concentrations among indigenous argentinean children living at high altitudes. Pediat Diabetes. 2013;14(3):203-10. https://doi. org/10.1111/pedi.12004

24. Dayer R, Haumont T, Belaieff W, Lascombes P. Idiopathic scoliosis: Etiological concepts and hypotheses. J Child Orthop. 2013;7(1):11-6. https://doi.org/10.1007/s11832-012-0458-3 PMid:24432053

25. Balioglu MB, Aydin C, Kargin D, Albayrak A, Atici Y, Tas SK, et al. Vitamin-D measurement in patients with adolescent idiopathic scoliosis. J Pediatr Orthop B. 2017;26(1):48-52. https://doi. org/10.1097/bpb.0000000000000320

PMid:27089048 
26. GozdzialskaA, Jaskiewicz J, Knapik-Czajka M, Drag J, Gawlik M, Ciesla M, et al. Association of calcium and phosphate balance, Vitamin D, PTH, and calcitonin in patients with adolescent idiopathic scoliosis. Spine (Phila Pa 1976). 2016;41(8):693-7. https://doi.org/10.1097/brs.0000000000001286

\section{PMid:27064335}

27. Batista R, Martins DE, Hayashi LF, Lazaretti-Castro M, Puertas EB, Wajchenberg M, et al. Association between Vitamin D serum levels and adolescent idiopathic scoliosis. Scoliosis. 2014;9(1):O45. https://doi.org/10.1186/1748-7161-9-s1-o45

28. Grivas TB, Vasiliadis E, Mouzakis V, Mihas C, Koufopoulos G.
Association between adolescent idiopathic scoliosis prevalence and age at menarche in different geographic latitudes. Scoliosis. 2006;1(1):9. https://doi.org/10.1186/1748-7161-1-9

PMid:16759371

29. Lam TP, Yip BH, Man GC, LeeWY, Tam EM, Lee KM, et al. Effective Therapeutic Control of Curve Progression Using Calcium and Vitamin D Supplementation for Adolescent Idiopathic Scoliosis-a Randomized Double-blinded Placebocontrolled Trial, $8^{\text {th }}$ International Conference on Children. Bristol, United Kingdom: BioScientifica; 2017. https://doi.org/10.1530/ boneabs.6.oc8 